\title{
Operational Philosophy for the Advanced Test Reactor National Scientific User Facility
}

J. Benson

J. Cole

J. Jackson

F. Marshall

D. Ogden

J. Rempe

M. C. Thelen

February 2013
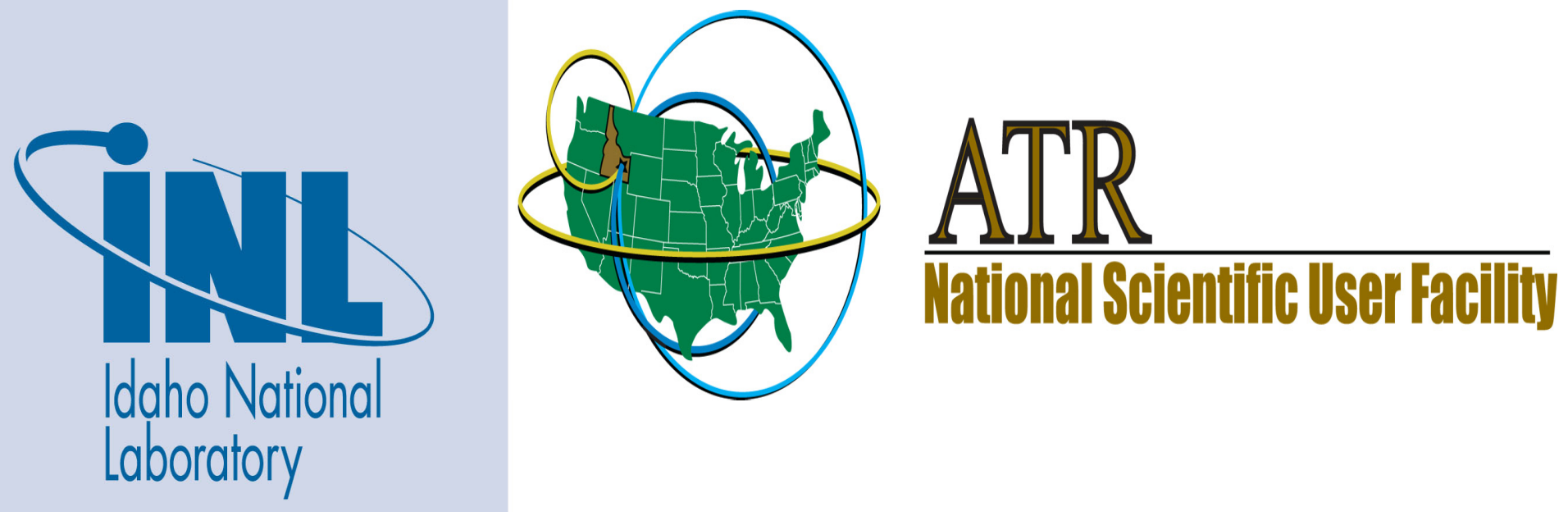


\section{DISCLAIMER}

This information was prepared as an account of work sponsored by an agency of the U.S. Government. Neither the U.S. Government nor any agency thereof, nor any of their employees, makes any warranty, expressed or implied, or assumes any legal liability or responsibility for the accuracy, completeness, or usefulness, of any information, apparatus, product, or process disclosed, or represents that its use would not infringe privately owned rights. References herein to any specific commercial product, process, or service by trade name, trade mark, manufacturer, or otherwise, does not necessarily constitute or imply its endorsement, recommendation, or favoring by the U.S. Government or any agency thereof. The views and opinions of authors expressed herein do not necessarily state or reflect those of the U.S. Government or any agency thereof. 


\section{Operational Philosophy for the Advanced Test Reactor National Scientific User Facility}

J. Benson, J. Cole, J. Jackson, F. Marshall, D. Ogden, J. Rempe, M. Thelen

February 2013

Idaho National Laboratory

Advanced Test Reactor National Scientific User Facility

Idaho Falls, Idaho 83415-3553

http://www.atrnsuf.inl.gov

Prepared for the

U.S. Department of Energy

Office of Nuclear Energy

Under DOE Idaho Operations Office

Contract DE-AC07-05ID14517 



\section{SUMMARY}

In 2007, the Department of Energy (DOE) designated the Advanced Test Reactor (ATR) as a National Scientific User Facility (NSUF). At its core, the ATR NSUF Program combines access to a portion of the available ATR radiation capability, the associated required examination and analysis facilities at the Idaho National Laboratory (INL), and INL staff expertise with novel ideas provided by external contributors (universities, laboratories, and industry). These collaborations define the cutting edge of nuclear technology research in high-temperature and radiation environments, contribute to improved industry performance of current and future light-water reactors (LWRs), and stimulate cooperative research between user groups conducting basic and applied research. To make possible the broadest access to key national capability, the ATR NSUF formed a partnership program that also makes available access to critical facilities outside of the INL. Finally, the ATR NSUF has established a sample library that allows access to pre-irradiated samples as needed by national research teams.

The ATR NSUF focuses on research proposed by universities, national laboratories, and industry. University-led projects must be aligned with programs of the DOE, Office of Nuclear Energy (DOE-NE), currently including Advanced Reactor Concepts, Light-Water Reactor Sustainability, Nuclear Energy Enabling Technology, and Fuel Cycle Research and Development (FCR\&D) programs. All projects are selected through a peer reviewed proposal process to ensure that the capability is open to anyone in the research community whose idea is determined to be of the highest quality of their peers while ensuring projects are relevant to the national programs.

To ensure that the most modern capability is available for the research community, the ATR NSUF also has a capability development program that focuses on three areas: addition of modern material science analysis equipment, development of advanced in core condition monitoring of experiments, and establishment of specialized equipment for the irradiation and analysis of materials critical to light water reactors.

Recognizing that radiation testing is a specialized skill, the ATR NSUF has also established a dedicated educational program to build new researchers who are vested in and capable of performing advanced research based on test reactor capability.

The ATR NSUF Program does not manage the day-to-day operations or maintenance of the facilities at the ATR or the Materials and Fuels Complex (MFC), nor does the ATR NSUF Program fund any of the facility operational and maintenance activities.

The ATR NSUF program office has the following specific primary functions:

- Select and execute non-proprietary reactor-based experiments, currently led by U.S. universities, through a proposal solicitation and peer review selection process, including proposal solicitations to be held jointly with other DOE programs and user facilities

- Select and execute non-proprietary post-irradiation examination (PIE) experiments, currently led by U.S. universities or national laboratories, through a proposal and peer review selection process

- Identify pathways for U.S. national laboratory staff to use the ATR NSUF capability

- Select and execute smaller Rapid Turnaround Proposals allowing researchers access to ATR NSUF equipment for limited size projects

- Coordinate partnership programs to take advantage of research capability across the U.S. to optimize the value of ATR-based experiments

- Maintain a sample library of previously irradiated materials against which proposals may be written for analysis in the ATR NSUF or other user facilities 
- Work with industry customers to define and execute proprietary or non-proprietary experiments, with specific emphasis on structural materials research requiring test reactor facilities and PIE

- Run the ATR NSUF educational program, in coordination with the INEST program, to expand the number of scientists and engineers interested in, and capable of, performing reactor-based experiments

- Maintain and expand, based on user requests, an in-pile instrumentation capability available for use in various ATR NSUF Material and Test Reactor (MTR) irradiations

- Define needed experimental capability that is desired by INL staff and external users of the ATR NSUF, and work with the INL facilities management and DOE Program staff to expand laboratory capabilities and resources to respond to the identified needs

- Identify technical areas other than reactor testing and PIE that could be added to the ATR NSUF program. These could include major thermal hydraulics facilities or fuel cycle facilities.

This document describes the goals of the ATR NSUF Program, and outlines the funding needed to successfully carry out the mission of the ATR NSUF for the time period 2013 - 2017. For this document, the term ATR NSUF is used to describe the ATR NSUF Program functions. 


\section{CONTENTS}

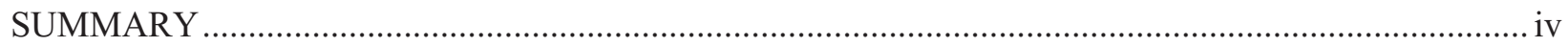

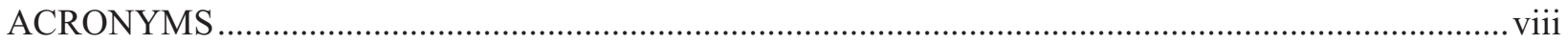

1. GOALS OF THE ADVANCED TEST REACTOR NATIONAL SCIENTIFIC USER

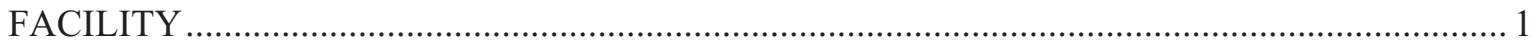

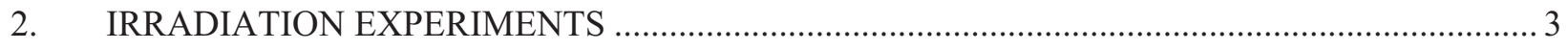

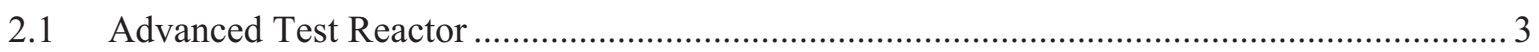

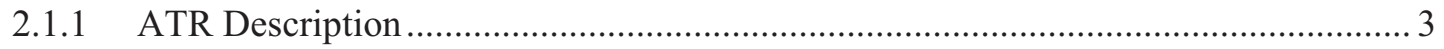

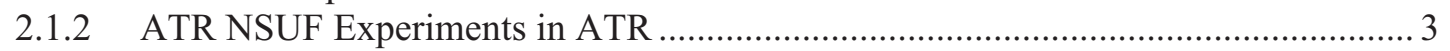

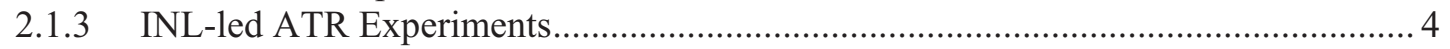

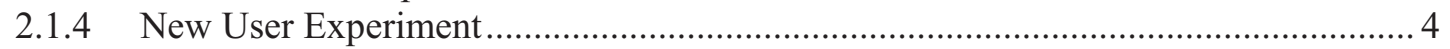

2.1.5 Transportation of ATR NSUF Experiments …................................................. 4

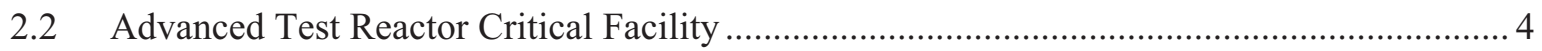

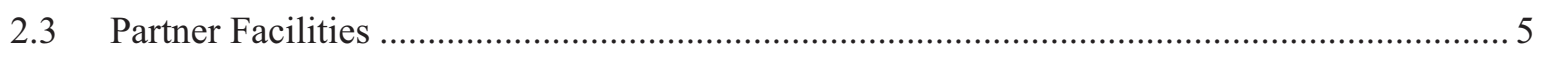

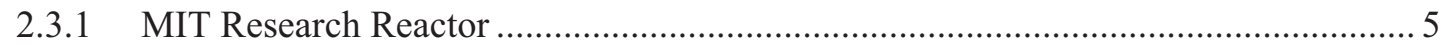

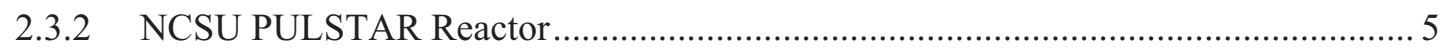

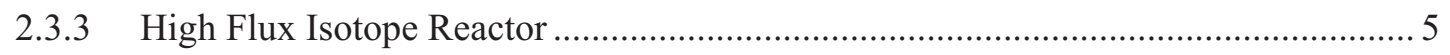

2.4 FY 2013 to 2017 Reactor Experiment Budget Requirements.............................................. 6

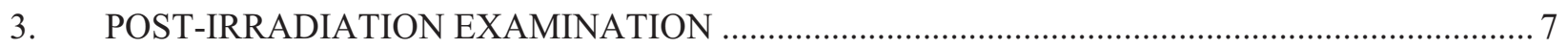

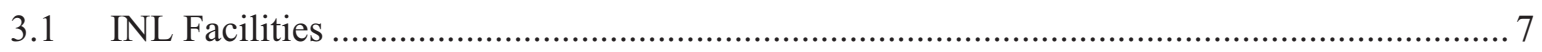

3.2 Partner Facilities ......................................................................................... 7

3.3 FY 2013 to 2017 PIE Budget Requirements...................................................................... 8

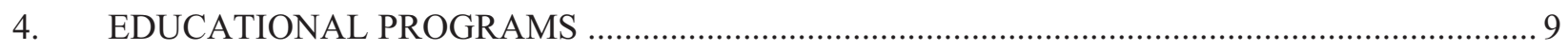

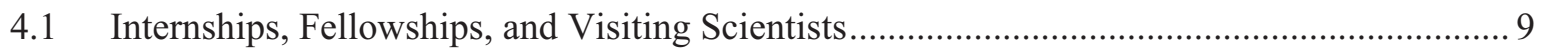

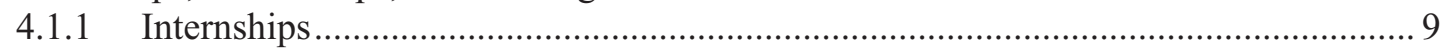

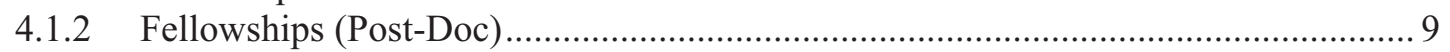

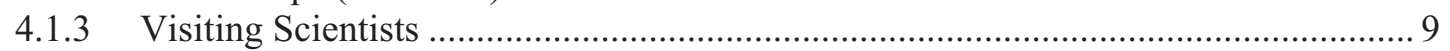

4.2 Research Forum, Educational Courses, and Content …............................................... 10

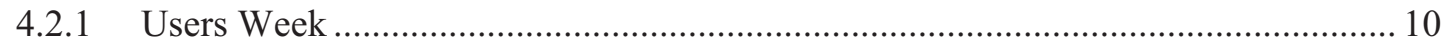

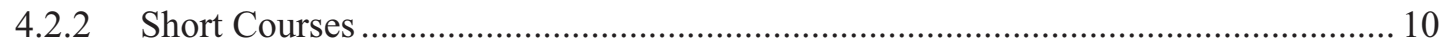

4.3 FY 2013 to 2017 ATR NSUF Education Program Budget Requirements............................ 10

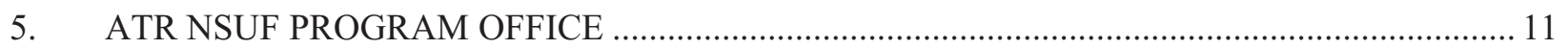

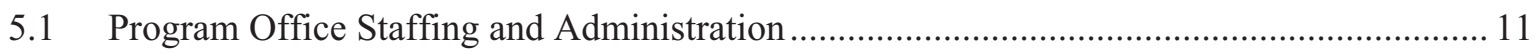

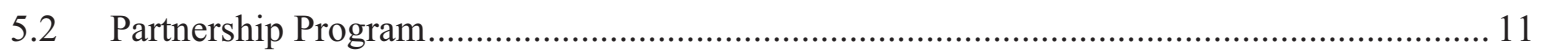

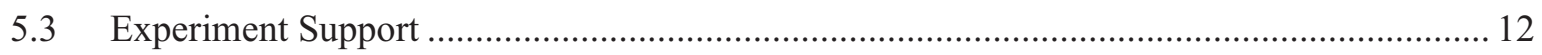

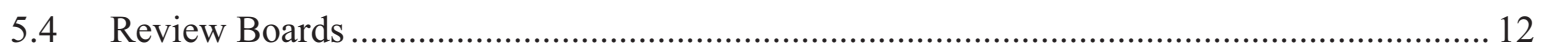

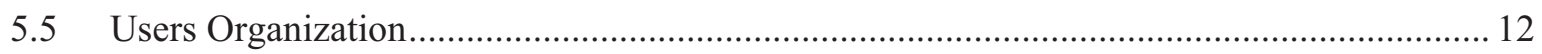

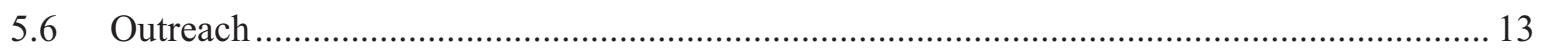

5.7 FY 2013 to 2017 Program Office Budget Requirements ................................................... 14 
6. REACTOR AND NON-REACTOR CAPABILITY ENHANCEMENTS …............................... 15

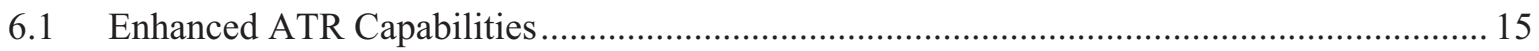

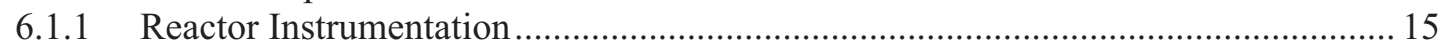

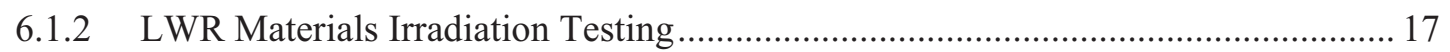

6.2 Post-irradiation Examination Capability …….................................................................... 17

6.2.1 Hot Fuel Examination Facility …..................................................................... 18

6.2.2 Irradiated Materials Characterization Laboratory …............................................... 18

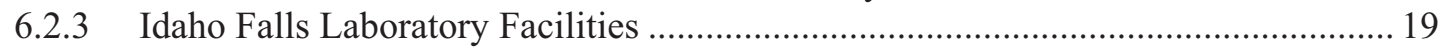

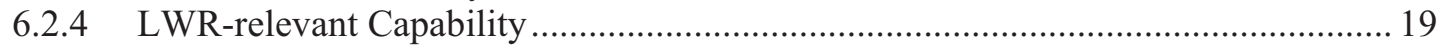

6.3 FY 2013 - 2017 Capability Enhancements Budget Requirements ..................................... 20

7. ATR NSUF Total Projected Funding Needs for FY 2013 to 2017 ............................................... 21

\section{TABLES}

Table 2-1. Estimated expenditures (in $\mathrm{K} \$$ ) to support irradiation experiments. .......................................... 6

Table 3-1. Estimated expenditures (in $\mathrm{K} \$$ ) to support post-irradiation examinations. ................................ 8

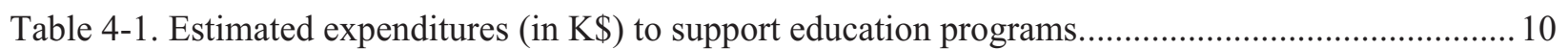

Table 5-1. Estimated expenditures (in K\$) to support the ATR NSUF Program Office activities............. 14

Table 6-1. Enhanced Sensor Technologies for ATR NSUF Irradiations................................................. 15

Table 6-2. Estimated expenditures (in K\$) to support capability enhancement. ......................................20

Table 7-1. Estimated expenditures (in K\$) to support all ATR NSUF functions.....................................2 21 


\section{ACRONYMS}

$\mu$-XRD micro X-ray Diffraction

AEM

Auger Electron Microprobe

AFM

Atomic Force Microscope

AL

Analytical Laboratory

ANIAC

ATR NUSF Industry Advisory Committee

ANS

APS

American Nuclear Society

ATR

Advanced Photon Source

ATRC

Advanced Test Reactor

BEA

ATR Critical facility

BES

Battelle Energy Alliance

BWR

Basic Energy Science

CAES

boiling water reactor

CEA

Center for Advanced Energy Studies

CONTE Conference on Nuclear Training and Education

$\mathrm{DC} \quad$ direct current

DOE Department of Energy

DOE-NE Department of Energy, Office of Nuclear Energy

EML Electron Microscopy Laboratory

EPMA Electron Probe Micro-Analyzer

EPRI Electric Power Research Institute

ESCA/XPS Electron Spectroscopy for Chemical Analysis/X-ray Photoelectron Spectroscopy

FASB Fuels and Applied Science Building

FCRD Fuel Cycle Research and Development

FEG-STEM field emission gun-scanning transmission electron microscope

FIB Focused Ion Beam

FRIS Fuel Rod Instrumentation System

FSRT Faculty and Student Research Team

HBWR Halden Boiling Water Reactor

HFEF Hot Fuels Examination Facility

HFIR High Flux Isotope Reactor

HSIS Hydraulic Shuttle Irradiation System

HTIR-TC High Temperature Irradiation Resistant ThermoCouple

HTTL High Temperature Test Laboratory

IASCC Irradiation Assisted Stress Corrosion Cracking

ICAPP International Congress on Advancements in Nuclear Power Plants

IFE/HRP Institutt for Energiteknikk (Institute for Energy Technology) at the Halden Reactor

Project

IMCL Irradiated Materials Characterization Laboratory

INL Idaho National Laboratory

INEST Institute for Nuclear Energy Science and Technology

LDRD Laboratory Directed Research and Development 


\begin{tabular}{ll} 
LEAP & Local Electrode Atom Probe \\
LIB & Line Item Building \\
LVDT & Linear Variable Differential Transformer \\
LWR & Light-Water Reactor \\
LWR-S & Light Water Reactor Sustainability \\
MaCS & Microscopy and Characterization Suite \\
MFC & Materials and Fuels Complex \\
MIT & Massachusetts Institute of Technology \\
MITR & Massachusetts Institute of Technology Research Reactor \\
MPFD & Micro-Pocket Fission Detector \\
MTR & Materials Test Reactor \\
NCSU & North Carolina State University \\
NGNP & Next Generation Nuclear Plant \\
NRAD & Neutron Radiography Reactor \\
NRC & Nuclear Regulatory Commission \\
NSUF & National Scientific User Facility \\
ORNL & Oak Ridge National Laboratory \\
PALM & Powered Axial Locator Mechanism \\
PIE & post-irradiation examination \\
PNNL & Pacific Northwest Nuclear Laboratory \\
PWR & pressurized water reactor \\
R\&D & research and development \\
REL & Research and Education Laboratory \\
RERTR & Reduced Enrichment for Research and Test Reactors \\
RTE & Rapid Turnaround Experiment \\
SCC & stress corrosion cracking \\
SRB & Scientific Review Board \\
SIMS & Secondary Ion Mass Spectroscopy \\
TEM & Transmission Electron Microscope \\
THWM & Transient Hot Wire Method \\
TMS & The Minerals, Metals and Materials Society \\
UCB & University of California, Berkeley \\
UW & University of Wisconsin Characterization Lab for Irradiated Materials \\
VHTR & Very High Temperature Reactor \\
XRD & X-ray Diffraction \\
\hline
\end{tabular}




\section{Operational Philosophy for the Advanced Test Reactor National Scientific User Facility}

\section{GOALS OF THE ADVANCED TEST REACTOR NATIONAL SCIENTIFIC USER FACILITY}

In 2007, the Department of Energy (DOE) designated the Advanced Test Reactor (ATR) as a National Scientific User Facility (NSUF). At its core, the ATR NSUF Program combines access to a portion of the available ATR radiation capability, the associated required examination and analysis facilities at the Idaho National Laboratory (INL), and INL staff expertise with novel ideas provided by external contributors (universities, laboratories, and industry). These collaborations define the cutting edge of nuclear technology research in high-temperature and radiation environments, contribute to improved industry performance of current and future light-water reactors (LWRs), and stimulate cooperative research between user groups conducting basic and applied research. To make possible the broadest access to key national capability, the ATR NSUF formed a partnership program that also makes available access to critical facilities outside of the INL. Finally, the ATR NSUF has established a sample library that allows access to pre-irradiated samples as needed by national research teams.

The ATR NSUF focuses on research proposed by universities, national laboratories, and industry. University-led projects must be aligned with programs of the DOE, Office of Nuclear Energy (DOE-NE), currently including Advanced Reactor Concepts, Light-Water Reactor Sustainability, Nuclear Energy Enabling Technology, and Fuel Cycle Research and Development (FCR\&D) programs. All projects are selected through a peer reviewed proposal process to ensure that the capability is open to anyone in the research community whose idea is determined to be of the highest quality of their peers while ensuring projects are relevant to the national programs.

To ensure that the most modern capability is available for the research community, the ATR NSUF also has a capability development program that focuses on three areas: addition of modern material science analysis equipment, development of advanced in core condition monitoring of experiments, and establishment of specialized equipment for the irradiation and analysis of materials critical to light water reactors.

Recognizing that radiation testing is a specialized skill, the ATR NSUF has also established a dedicated educational program to build new researchers who are vested in and capable of performing advanced research based on test reactor capability.

The ATR NSUF Program does not manage the day-to-day operations or maintenance of the facilities at the ATR or the Materials and Fuels Complex (MFC), nor does the ATR NSUF Program fund any of the facility operational and maintenance activities..

The ATR NSUF program office has the following specific primary functions:

- Select and execute non-proprietary reactor-based experiments, currently led by U.S. universities, through a proposal solicitation and peer review selection process, including proposal solicitations to be held jointly with other DOE programs and user facilities

- Select and execute non-proprietary post-irradiation examination (PIE) experiments, currently led by U.S. universities or national laboratories, through a proposal and peer review selection process

- Identify pathways for U.S. national laboratory staff to use the ATR NSUF capability 
- Select and execute smaller Rapid Turnaround Proposals allowing researchers access to ATR NSUF equipment for limited size projects

- Coordinate partnership programs to take advantage of research capability across the U.S. to optimize the value of ATR-based experiments

- Maintain a sample library of previously irradiated materials against which proposals may be written for analysis in the ATR NSUF or other user facilities

- Work with industry customers to define and execute proprietary or non-proprietary experiments, with specific emphasis on structural materials research requiring test reactor facilities and PIE

- Run the ATR NSUF educational program, in coordination with the INEST program, to expand the number of scientists and engineers interested in, and capable of, performing reactor-based experimentsMaintain and expand, based on user requests, an in-pile instrumentation capability available for use in various ATR NSUF Material and Test Reactor (MTR) irradiations

- Define needed experimental capability that is desired by INL staff and external users of the ATR NSUF, and work with the INL facilities management and DOE Program staff to expand laboratory capabilities and resources to respond to the identified needs

- Identify technical areas other than reactor testing and PIE that could be added to the ATR NSUF program. These could include major thermal hydraulics facilities or fuel cycle facilities.

This document describes the goals of the ATR NSUF Program, and outlines the funding needed to successfully carry out the mission of the ATR NSUF for the time period 2013 - 2017. For this document, the term ATR NSUF is used to describe the ATR NSUF Program functions. 


\section{IRRADIATION EXPERIMENTS \\ 2.1 Advanced Test Reactor}

\subsubsection{ATR Description}

The ATR is a multipurpose irradiation test facility that has supported fuel and material testing for the U.S. government for over 45 years of continued operation. The ATR is operated at approximately 110 MWt (compared to a maximum design operating power of $250 \mathrm{MWt}$ ), and at that power can provide thermal neutron fluxes of $4.4 \times 10^{14}$ neutrons per square centimeter per second $\left(\mathrm{n} / \mathrm{cm}^{2}-\mathrm{s}\right)$ and maximum

fast $(\mathrm{E}>1.0 \mathrm{MeV})$ neutron fluxes of $2.2 \times 10^{14} \mathrm{n} / \mathrm{cm}^{2}-\mathrm{s}$. The testing positions vary in diameter from 0.5 to 5.0 inches, and all are the length of the active core height, 48 inches.

Four types of irradiation configurations are available to experimenters: static-sealed capsule tests with passive instrumentation, instrumented lead tests with active instrumentation for measurement and control of specific testing parameters, pressurized-water reactor (PWR) loops that enable testing in a flowing water environment with commercial PWR prototypic conditions, and hydraulic shuttle irradiation system (HSIS) experiments, where the test specimens can be inserted and removed from the ATR core for durations shorter than an operating cycle. In the PWR loop tests there is the capability to independently control temperature, pressure, and water chemistry, and have dedicated operators to monitor control the loops and loop experiments. It is also possible to perform transient testing using the Powered Axial Locator Mechanism (PALM), a mechanically driven device that will move experiments into and out of the reactor core within the reactor vessel.

Currently, there are six PWR experiment loops operational, and five are used by the Naval Reactors Program. Previously, there were nine operational PWR experiment loops. During the 1990s, due to decreased testing needs, the INL contractor decided to remove four PWR loops from service; however, current needs now dictate refurbishment and reinstallation of an additional PWR loop, which was installed in the center flux trap. This additional loop capability, designated "Loop 2A," became operational and available to ATR NSUF users and other customers starting in FY 2013. Battelle Energy Alliance (BEA) was responsible for reactivating Loop 2A and ensuring that the loop hardware is operational, however, the test train design, assembly, and handling equipment was not included in this reactivation project. To ensure that the PWR loop can be fully utilized, the ATR NSUF assumed the responsibility to ensure that all ancillary PWR experiment loop systems and hardware are fully operational to support the PWR loop testing when Loop 2A became operational.

\subsubsection{ATR NSUF Experiments in ATR}

The initial ATR NSUF experiments irradiated in the ATR were static capsules. All experiments tested reactor materials, without fissile material, to simplify the experiment configuration designs and experiment assembly. Subsequent proposal calls included more complex experiments, such as instrumented lead experiments, fissile material, and PWR loops. Since the designation of ATR as an NSUF, the ATR NSUF experiments in ATR have included static capsule, instrumented lead, and HSIS experiments. The first ATR NSUF PWR loop experiment, for the Electric Power Research Institute (EPRI), will begin irradiation in 2013. Following this initial set of irradiation experiments, the Loop 2A will be available to all ATR NSUF users via the proposal process. The estimated experiment funding needs (shown in table 2-1) are based on assuming a mix of experiment types in future proposal calls. Overall, for optimum utilization of the irradiation capability, the ATR NSUF expects to award approximately 12 to 14 new ATR experiments each year. The specific combination of experiments awarded will depend on the user proposals. Thus, once an experiment is accepted for implementation, a specific cost estimate will be prepared to ensure that the awarded experiment can be included in the overall ATR NSUF funding profile. Each new experiment adds additional reactor testing designs to the INL repertoire, as well as engages an INL staff scientist in cutting-edge nuclear technology research. The ATR will have an extended outage (approximately six months) in 2016 for the core internals changeout. 
Experiments awarded prior to this time will be evaluated to be sure that the experiment can either be completed prior to this outage or will not be compromised by a lengthy pause in the irradiation time. Likewise, reactor irradiation experiments will continue to be awarded in 2015 and 2016 since there is substantial preparation time prior to the irradiation period. Thus, the "steady state" award rate for irradiation experiments in ATR is not expected to be impacted by this outage schedule.

\subsubsection{INL-led ATR Experiments}

To fully take advantage of the NSUF concept that is implemented at other DOE complex facilities, the ATR NSUF has planned to offer research funding to INL staff to study the effects of radiation on materials. These experiments will be competed within INL (similar to the current laboratory-directed research and development [LDRD] program), and awards will be decided by the ATR NSUF Scientific Director. These INL-led research projects are planned to begin in 2014. They will be part of the overall program budget and expected to be funded at approximately $10 \%$ of the overall experiment (reactor plus PIE) budget.

\subsubsection{New User Experiment}

In an effort to increase the capability of the ATR NSUF user community to understand the irradiation experiment process, the ATR NSUF program has offered a New User Experiment, to be led by the INL technical staff. An experiment is defined by the ATR NSUF Scientific Director, relative to the material to be irradiated and the irradiation conditions, and universities are invited to participate in the experiment design and development. There is no peer reviewed proposal for this experiment as INL will be responsible for making all the technical decisions and setting the research objectives. It is envisioned that this will be offered biannually as a capsule experiment.

\subsubsection{Transportation of ATR NSUF Experiments}

For all experiments irradiated at ATR, the specimens must be transported off the ATR site to hot cells for examination. The most commonly used hot cell is the Hot Fuels Examination Facility (HFEF) at the Materials and Fuels complex (MFC). Due to expected high dose rates, most experiments will need to be disassembled at HFEF, then transported again to other or multiple hot cells and laboratories for investigations. The ATR NSUF Program assumes the cost of all ATR NSUF experiment specimen transportation. In 2013, the standard shipping container used to transport experiments from ATR is the GE-2000 cask. It is anticipated that this will continue to be the most commonly used shipping container. Effort and costs associated with identifying and qualifying different shipping containers for future use are not included in the ATR NSUF planning basis.

\subsection{Advanced Test Reactor Critical Facility}

The ATR Critical facility (ATRC) is a full-size, low-power, pool-type nuclear replica of the ATR, and is located in the ATR building in an extension of the ATR canal. Its normal operating power level is about $100 \mathrm{~W}$ with a maximum power rating of $5 \mathrm{~kW}$. The effect of an experiment on core reactivity must be known with good accuracy and precision before it can be placed in the ATR core. Sometimes it is necessary to determine this experimentally in the ATRC, which is designed to evaluate prototypical experiments before the actual experiments are irradiated in the ATR. When ATRC testing is necessary, experimenters furnish prototypes of capsule experiments.

The ATRC provides reactor physics data that contribute to evaluating (a) the worth and calibrations of control elements, (b) excess reactivities and charge lifetimes, (c) thermal and fast neutron distributions, (d) gamma heat generation rates, (e) fuel loading requirements, (f) effects of inserting and removing experiments and experiment void reactivities, and $(\mathrm{g})$ temperature and void reactivity coefficients. As a part of the ATR NSUF, users are invited to propose ATRC experiments that could be performed to validate modeling codes, test new instrumentation, or perform multiple reactivity measurements. 


\subsection{Partner Facilities}

Currently, the ATR NSUF has established three partnerships with university and national laboratory reactor facilities for reactor use to support ATR NSUF irradiation projects. These facilities are Massachusetts Institute of Technology Research Reactor (MITR), North Carolina State University (NCSU) PULSTAR Reactor, and the High Flux Isotope Reactor (HFIR) at Oak Ridge National Laboratory (ORNL). All reactor experiment proposals submitted through the solicitation process will be distributed to these reactor facilities for review to determine if the proposed experiment can be performed in any of these facilities. Additional partner facilities may be added in the future, as the need for additional irradiation capacity is needed or as unique capabilities are available at other locations.

\subsubsection{MIT Research Reactor}

The MITR is a tank-type research reactor, currently licensed for $5 \mathrm{MWt}$ operation. The reactor has two tanks: an inner one for the light-water coolant/moderator and an outer one for the heavy-water reflector. A graphite reflector surrounds the heavy-water tank. The core is normally configured with three positions available for in-core experiments. The compact core can provide fast and thermal neutron fluxes up to $10^{14}$ and $5 \times 10^{13} \mathrm{n} / \mathrm{cm}^{2}-\mathrm{s}$, respectively. The second type of in-core facility encompasses a variety of more complex irradiation rigs that are expressly designed for a particular purpose. These include LWR loops used to study various aspects of coolant chemistry, passively and actively loaded mechanical tests under LWR conditions, corrosion test loops for advanced clad materials, a test of internally and externally cooled annular fuel, and an irradiation test for high-temperature gas reactor materials at temperatures from approximately 1000 to $1600^{\circ} \mathrm{C}$. The modular design and small size of these facilities makes it possible to design and construct new facilities for specific purposes at moderate cost.

A variety of in-core and support instrumentation and measurement can be provided to support in-core loop irradiation. Thermocouple temperature, electrochemical corrosion potential and other electrode measurements, direct current (DC) potential drop strain, and crack growth measurement have all been used in experiments. A wide variety of parameters are routinely monitored and recorded at out-of-core locations for the in-core facilities, including temperature, pressure, flow, dissolved hydrogen and oxygen, and conductivity.

\subsubsection{NCSU PULSTAR Reactor}

The NCSU PULSTAR Reactor is a $1 \mathrm{MWt}$ pool-type research reactor with 4\% enriched, pin-type fuel consisting of uranium dioxide pellets in zircaloy cladding. This fuel gives the PULSTAR Reactor response characteristics that are very similar to commercial light-water power reactors. These characteristics enable teaching experiments to measure moderator temperature and power reactivity coefficients, including Doppler feedback. Combined reactivity feedback effects are demonstrated in start-up and power operation. The PULSTAR has a variety of irradiation facilities used for teaching and analytical services, such as neutron imaging and neutron activation analysis. Fixed-beam facilities are used for prompt neutron capture gamma analysis and neutron/matter interaction studies.

\subsubsection{High Flux Isotope Reactor}

The HFIR provides a high flux (up to $5 \times 10^{15} \mathrm{n} / \mathrm{cm}^{2}$-s thermal) material irradiation test capabilities that are similar to those available at the ATR. There is one large flux trap that can be configured to suit a variety of test configurations and several reflector irradiation positions for additional material irradiations. In-core irradiations are performed for medical, industrial, and isotope production as well as research programs on severe neutron damage to materials. 


\subsection{FY 2013 to 2017 Reactor Experiment Budget Requirements}

Table 2-1 lists the estimated costs (in K\$) for the ATR experiments. These costs are estimated as FY 2013 as a cost basis and the out year costs are escalated. All of the funds listed in the table would be spent internal to INL or at the ATR NSUF partner facilities. Each experiment benefits INL by:

- Engaging an INL staff member in the research

- Adding new experimental designs to the options available at ATR

- Establishing a mechanism for testing advanced in-pile instrumentation.

- Establishing scientific working relationships with other national reactor testing facilities.

Table 2-1. Estimated expenditures (in $\mathrm{K} \$$ ) to support irradiation experiments.

\begin{tabular}{|c|c|c|c|c|c|}
\hline Budget Item & 2013 & 2014 & 2015 & 2016 & 2017 \\
\hline ATR Capsule Experiments ${ }^{a, b, c}$ & $\$ 896$ & $\$ 2,250$ & $\$ 2,295$ & $\$ 3,901$ & $\$ 4,775$ \\
\hline $\begin{array}{l}\text { ATR Instrumented Lead } \\
\text { Experiments a, d }\end{array}$ & $\$ 432$ & $\$ 500$ & $\$ 3,060$ & $\$ 3,121$ & $\$ 3,184$ \\
\hline ATR Loop Experiments ${ }^{\mathrm{a}, \mathrm{e}}$ & $\$ 528$ & $\$ 500$ & $\$ 2,040$ & & $\$ 2,122$ \\
\hline ATR HSIS Experiments ${ }^{a, f}$ & $\$ 719$ & $\$ 700$ & $\$ 1,428$ & $\$ 2,913$ & $\$ 2,971$ \\
\hline ATRC Test ${ }^{\mathrm{a}, \mathrm{g}}$ & $\$ 225$ & & $\$ 153$ & $\$ 156$ & $\$ 159$ \\
\hline New User Experiment & $\$ 74$ & $\$ 700$ & & $\$ 714$ & \\
\hline ATR Coordination $^{\mathrm{h}}$ & $\$ 1,410$ & $\$ 1,438$ & $\$ 1,467$ & $\$ 1,846$ & $\$ 1,883$ \\
\hline Experiment Shipments & $\$ 600$ & $\$ 510$ & $\$ 520$ & $\$ 531$ & $\$ 541$ \\
\hline $\begin{array}{l}\text { Reactor Experiments at Partner } \\
\text { Facilities }{ }^{\mathrm{i}}\end{array}$ & $\$ 436$ & $\$ 445$ & $\$ 454$ & $\$ 463$ & $\$ 472$ \\
\hline INL Directed R\&D ${ }^{j}$ & & $\$ 700$ & $\$ 1,000$ & $\$ 1,300$ & $\$ 1,500$ \\
\hline Total Reactor Experiments & $\$ 5,320$ & $\$ 7,743$ & $\$ 12,417$ & $\$ 14,946$ & $\$ 17,608$ \\
\hline
\end{tabular}

a. In 2014, the mortgages from prior year experiments will be paid off and new experiments from 2014 forward will be fully funded the first year of the experiment award.

b. Capsule experiments will increase from one award in 2014 to a steady state 6 per year in 2016 .

c. All experiment awards will be based on proposal submittals and peer reviews. The exact mix of experiment types to be awarded in a single year could be different than listed here.

d. One instrumented lead experiment will be awarded each year.

e. One loop experiment will be awarded biannually.

f. HSIS experiments will increase from one per year to a steady state of four per year.

g. One ATRC experiment will be awarded each year starting in 2015.

$\mathrm{h}$. One experiment manager will be added to the ATR coordination in 2016.

i. These costs reflect only the research performed at the partner facility, not base operations or maintenance, and awards are dependent on the proposals written and the results of the peer reviewsThese funds will be competed, with INL-internal peer review and Scientific Director selections. 


\section{POST-IRRADIATION EXAMINATION}

\subsection{INL Facilities}

Steady-state full operation of the ATR NSUF research program includes thirty PIE projects per year as a result of university and INL-directed non-proprietary irradiation experiments, PIE-only experiments, and rapid turnaround experiments (RTEs). Additionally, materials degradation testing has become a priority for industry, and will drive a large post-irradiation testing program. The ATR NSUF makes available many of the materials and fuels irradiated as part of previous DOE or industry programs, or excess materials from ATR NSUF irradiations, for PIE. Inventory, tracking and pedigree of these materials is accomplished through a material database or "Library" maintained by the ATR NSUF staff. Many of these items have not been examined or now merit additional examination because of advances in technology or understanding. These PIE-only or rapid turnaround experiments (depending on scope of work) utilize materials currently stored at INL or other facilities in relatively low-cost projects that add to the scientific understanding of material irradiation behavior. PIE-only and rapid turnaround projects also occur on a short time scale relative to irradiation experiments, allowing more rapid publication of results.

The facilities at the MFC and the Center for Advanced Energy Studies (CAES) are the primary tools available at INL for post-irradiation examinations. These examinations are conducted using the equipment currently located in the HFEF, Electron Microscopy Laboratory (EML), Analytical Laboratory (AL), Fuels and Applied Science Building (FASB) and the CAES Microscopy and Characterization Suite (MaCS). The HFEF is used to conduct basic destructive and non-destructive examinations and plays an essential role in sample size reduction and distribution. The HFEF is the only facility on the INL site where large shipping casks can be accepted and unloaded and irradiation experiments disassembled. Specialized equipment in the EML, AL, FASB, and MACS are used as necessary for each experiment, and ATR NSUF funding is used to complete the examinations required.

There is currently some research ongoing within the ATR NSUF program to develop the mechanical testing capability necessary to support LWR-related materials research. This is included in the PIE section of this document and the associated budget, because there are samples being tested as the development progresses. This is expected to continue for the duration of the program, as this testing is far from mature at this time. The effort includes two full time scientists.

As the number of shipments between the ATR and HFEF continues to increase, it is essential that the laboratory invest in a cost efficient INL sample transportation interface between these two facilities as well as streamline intra facility and external transfers. This is a lab-wide issue, thus efforts to resolve it are not included in the ATR NSUF program strategy.

\subsection{Partner Facilities}

Currently, the ATR NSUF has established nine partnerships with university and national laboratory irradiation and characterization facilities to conduct PIE. The facilities, which are all available for any ATR NSUF project, include the University of Nevada Las Vegas Electron Microscopy Laboratory, the University of Michigan Ion Beam Laboratory and Irradiated Materials Complex, the University of Wisconsin (UW) Characterization Lab for Irradiated Materials, the Illinois Institute of Technology Materials Collaborative Access Team (MRCAT) beam-line at the Advanced Photon Source (APS), PIE facilities at ORNL, NCSU, University of California Berkeley, Purdue University and Pacific Northwest National Laboratory. Any reactor experiment or PIE project can be distributed to these facilities for testing and analysis. Some research will require use of more than one partner facility. Additional partner facilities may be added in the future. 


\subsection{FY 2013 to 2017 PIE Budget Requirements}

Budget projections tabulated here include funds necessary from 2013 to 2017 to perform PIE on university experiments (see Table 3-1).

Table 3-1. Estimated expenditures (in $\mathrm{K} \$$ ) to support post-irradiation examinations.

\begin{tabular}{|c|c|c|c|c|c|}
\hline Budget Item & 2013 & 2014 & 2015 & 2016 & 2017 \\
\hline PIE Coordination $^{a}$ & $\$ 545$ & $\$ 556$ & $\$ 567$ & $\$ 928$ & $\$ 947$ \\
\hline PIE performed at INL ${ }^{b, c}$ & $\$ 1,559$ & $\$ 2,339$ & $\$ 2.385$ & $\$ 2,547$ & $\$ 3,464$ \\
\hline PIE-Only Experiments at INL ${ }^{\mathrm{d}}$ & & $\$ 510$ & $\$ 2,601$ & $\$ 3,714$ & $\$ 4,871$ \\
\hline Rapid Turnaround Experiments ${ }^{\mathrm{e}}$ & $\$ 170$ & $\$ 204$ & $\$ 708$ & $\$ 1,443$ & $\$ 2,208$ \\
\hline MaCS Funding & $\$ 469$ & $\$ 478$ & $\$ 488$ & $\$ 498$ & $\$ 508$ \\
\hline Mechanical Testing ${ }^{\mathrm{f}}$ & $\$ 516$ & $\$ 700$ & $\$ 714$ & $\$ 546$ & $\$ 557$ \\
\hline PIE at Partner Facilities ${ }^{\mathrm{g}}$ & $\$ 436$ & $\$ 445$ & $\$ 454$ & $\$ 463$ & $\$ 472$ \\
\hline INL Directed R\&D ${ }^{\mathrm{h}}$ & & $\$ 500$ & $\$ 800$ & $\$ 900$ & $\$ 1,000$ \\
\hline Total Post Irradiation Examination & $\$ 3,695$ & $\$ 5,732$ & $\$ 8,712$ & $\$ 11,039$ & $\$ 14,026$ \\
\hline
\end{tabular}

a. Another PIE project manager will be added to PIE coordination in 2016.

b. In 2015 , the mortgages from prior year experiments will be paid off and new experiments from 2015 forward will be fully funded the first year of the experiment award.

c. The number of PIE experiments will increase to a steady state of 12 per year in 2018 .

d. The number of PIE-only experiments will increase to a steady state of nine per year in 2017 .

e. The number of RTEs will increase to a steady state of 16 per year in 2018.

f. It is expected that these costs will decrease due to increased industry funding in 2016.

g. These costs reflect only the research performed at the partner facility, not base operations or maintenance, and awards are dependent on the proposals written and the results of the peer reviews.

h. These funds will be competed, with INL-internal peer review and Scientific Director selections. 


\section{EDUCATIONAL PROGRAMS}

A mature ATR NSUF educational program seeks to establish a cadre of nuclear energy researchers, facilitating the advancement of nuclear science and technology through reactor-based testing. The educational program also increases the ATR NSUF Program value by developing strategic partnerships with universities and help inform the academic user community on nuclear energy issues and tools available to address research questions. ATR NSUF education programs are used to maximize access and serve as a resource to an informed, engaged, and equipped academic user community.

Prior to the establishment of the ATR NSUF Program, access for faculty and students to cutting-edge and one-of-a-kind tools needed to conduct reactor-based research in nuclear science and technology, fuels, and materials has been limited. To bridge this gap the ATR NSUF uses focused internships, postdoctoral fellowships, and faculty/student exchanges to enable researchers to gain access to key mentors, world-class facilities, and equipment. In addition, an ATR NSUF Users Week has been established, and ATR NSUF Program staff have conducted research forums and specialized courses. A major emphasis of all education programs is to allow for maximum interaction and access to the critical components of the nation's experimental nuclear research infrastructure.

\subsection{Internships, Fellowships, and Visiting Scientists}

\subsubsection{Internships}

Internships are the direct mechanism by which undergraduate and graduate students can access the ATR NSUF and be introduced to mentors. Each year, approximately nine interns are exposed to research and gain experience with tools in reactor-based nuclear science and technology. The number of interns should be increased to approximately 15 each year. Typically interns spend 10 to 12 weeks at INL in the summer on a paid internship sponsored by the ATR NSUF. Graduate students may use their intern experience to conduct thesis or dissertation research. This experience is more focused than the undergraduate internship and can last for up to one year. Internships will also be used to support the increased impact of the ATR NSUF on facility operations and ongoing research. Some interns may be used to support ATR engineering, experiment design and analysis, and applications of irradiated material examination techniques and analysis. Interns in this program are targeted as a potential pool of employees who are familiar with ATR NSUF work. These interns are identified and targeted to be recruited and hired before they graduate using the INL contingent job offer process.

\subsubsection{Fellowships (Post-Doc)}

Post-doctoral appointments are used to provide recent doctoral graduates an opportunity for a short (up to 3 years) duration appointment in areas that are in alignment with current or future ATR NSUF research areas. The Post-doc appointment will be on focused on PIE research, developing new techniques to be used in irradiated fuels and materials research, or help build ATR NSUF knowledge of new reactor based instrumentation. This opportunity is expected to become available in FY 2014.

\subsubsection{Visiting Scientists}

The ATR NSUF education program has two programs for visiting scientists and students. The Faculty and Student Research Team (FSRT) program awards faculty-led team contracts to partner with an INL mentor and work on building capability/knowledge needed to support ATR NSUF research. In addition, teams gain an understanding of INL, access to INL research facilities, build technical knowledge, and establish relationships with INL researchers. The ATR NSUF also uses an existing INL program called the Faculty and Staff Exchange program. INL staff participants in this program are sent to universities or other research facilities, such as the Institute for Energy Technology at the Halden Reactor Project (IFE/HRP) in Norway and Commissariat a'l'E'nergie Atomique et aux Energies Alternatives (CEA) in 
France. Additionally, university faculty can visit INL. Researchers in this program are encouraged to spend time at a university/INL to teach, perform research, collaborate, and be involved in campus/laboratory life.

\subsection{Research Forum, Educational Courses, and Content}

\subsubsection{Users Week}

Annually, the ATR NSUF hosts a "Users Week" to provide a venue to inform the nuclear science and technology community of current issues and the tools and facilities available through the use of the ATR NSUF to address these issues. Users Week is comprised of a research forum that discusses current collaborative nuclear technology research being conducted in the ATR NSUF. Sessions are also held to familiarize participants with the ATR NSUF research facilities and capabilities. Discussions are held to facilitate potential future industry-laboratory-university collaborations. Users Week also has extended courses on fuels and materials and how to conduct and execute irradiation experiments. Additional courses will be developed in future years. Up to 50 travel stipends are available annually to cover travel expenses to faculty and student participants.

\subsubsection{Short Courses}

Portions of courses from Users Week are available as short-courses to be presented at universities, technical society meetings, or technical meetings. As examples, short courses are adapted from the Experimenters' Course or the Fuels and Materials course.

\subsection{FY 2013 to 2017 ATR NSUF Education Program Budget Requirements}

Table 4-1. Estimated expenditures (in K\$) to support education programs.

\begin{tabular}{|l|c|c|c|c|c|}
\hline \multicolumn{1}{|c|}{ Budget Item $^{\prime}$} & $\mathbf{2 0 1 3}$ & $\mathbf{2 0 1 4}$ & $\mathbf{2 0 1 5}$ & $\mathbf{2 0 1 6}$ & $\mathbf{2 0 1 7}$ \\
\hline Student internships $^{\text {a }}$ & $\$ 183$ & $\$ 250$ & $\$ 318$ & $\$ 325$ & $\$ 332$ \\
\hline Users Week $^{\prime}$ & $\$ 160$ & $\$ 163$ & $\$ 167$ & $\$ 170$ & $\$ 173$ \\
\hline FSRT $^{\text {b }}$ & $\$ 80$ & $\$ 160$ & $\$ 163$ & $\$ 167$ & $\$ 173$ \\
\hline Fellowships $^{\prime}$ & & $\$ 180$ & $\$ 184$ & $\$ 187$ & $\$ 191$ \\
\hline Other & $\$ 317$ & $\$ 323$ & $\$ 330$ & $\$ 336$ & $\$ 343$ \\
\hline Total Educational Programs & $\mathbf{\$ 7 4 0}$ & $\mathbf{\$ 1 , 0 7 6}$ & $\mathbf{\$ 1 , 1 6 2}$ & $\mathbf{\$ 1 , 1 8 5}$ & $\mathbf{\$ 1 , 2 0 9}$ \\
\hline
\end{tabular}

a. The number of internships will increase from 9 in 2013 to a steady state of 15 in 2015 .

b. There will be two FSRTs in 2013 and three or four in subsequent year, depending on proposals snd funding needed for each team. 


\section{ATR NSUF PROGRAM OFFICE 5.1 Program Office Staffing and Administration}

A properly staffed program office is necessary for the ATR NSUF program to accomplish its mission of providing access to world-class facilities for nuclear energy researchers for the advancement of nuclear science and technology. The program office is responsible for providing both technical and non-technical support to users. Maintaining the existing functions and activities and identifying key hires for the future will ensure that users have the best possible experience.

Technical expertise is critical to the success of the ATR NSUF research, and includes the ATR NSUF program manager, chief scientist, and an industry program lead along with a variety of INL scientists and engineers. These technical experts provide support to users in many ways, including assisting in the development of strong proposals. They also support the program office by performing reviews on submitted proposals to determine facility feasibility and DOE-NE program relevance. In addition to independent peer reviews, ATR NSUF convenes a panel committee of three technical experts who perform a final overall review and ranking of proposals. In this way ATR NSUF ensures that the best science is awarded.

The administration of key non-technical items creates a foundation for excellence in educating and assisting users. These activities include development and execution of user agreements and subcontracts for experiments, subcontracts for strategic partnerships, website interfaces, outreach activities (exhibits, support of external symposia, etc.), supporting student users working at INL, and working with the ATR NSUF Users Organization. Staffing for non-technical activities currently includes a full time program administrator, project manager, financial analyst, administrative assistant, communications liaison, and a part time web developer and graphic artist. As the number and complexity of experiments awarded increases, additional technical and non-technical staff will be required to ensure adequate support for user research.

\subsection{Partnership Program}

The Partnership Program was developed in recognition that establishment of strong ties with universities and other national laboratories not only adds capabilities that may be otherwise under-utilized or unavailable in the existing facilities of the ATR NSUF, but also builds the framework for strengthening collaborative, nuclear research in the U.S. Through this unique aspect of the program, research opportunities have grown exponentially.

Facilities interested in joining the partnership submit a brief proposal using the template provided on the ATR NSUF website. The call for partner proposals is always open, and proposals are reviewed as they are received. The reviews are performed by three experts who determine if there is synergy with existing ATR NSUF capabilities. If a proposal passes review, the facility is added. A User Guide of the new capabilities is developed by the partner and posted on the ATR NSUF website. Once a partner facility is accepted, proposals are reviewed and awarded to the facility that can best accommodate the research. If a partner facility is chosen to perform a research project, funds are provided to the partner facility through a subcontract to cover the costs of performing the research. ATR NSUF currently has 10 partner facilities including: Illinois Institute of Technology; Massachusetts Institute of Technology; North Carolina State University; Oak Ridge National Laboratory; Pacific Northwest National Laboratory; Purdue University; University of California, Berkeley; University of Michigan-Wisconsin; University of Nevada, Las Vegas and University of Wisconsin. This program has generated a good deal of interest among universities and other national laboratories and it is expected partner facilities will continue to be added in the years to come. Estimated costs for experiments performed at partner facilities are included in Tables 2-1 and 3-1, and reflect only the cost for the user research at the partner facility not base 
operation or maintenance. Costs for administering the contracts for these experiments are included in the Program Office cost estimates.

In addition to the partners listed above, the program developed a slightly different model for collaboration with the Center for Advanced Energy Studies (CAES) in Idaho Falls. Through this collaboration, the MaCS laboratory was fitted by the INL with a number of specialized instruments including a focused ion beam, a transmission electron microscope, a local electrode atom probe, a nanoindenter with an atomic force microscope, and a scanning electron microscope. Boise State University provides the technical staff to support research experiments in this facility. Once the instruments were purchased and installed, a service agreement was established between ATR NSUF and CAES that allows ATR NSUF researchers access to these instruments through the proposal submission and award process. Low-dose radioactive samples can be handled in this laboratory, and a rapidly growing number of ATR NSUF experiments are being performed in this facility.

Another strategic partnership effort currently being piloted is the cooperative research process. The idea behind this effort is to grant researchers proposing to other user facilities access to previously irradiated materials from the ATR NSUF sample library. The Advanced Photon Source (APS) at Argonne National Laboratory was the first to show interest, and two pilot proposals were initiated through the process in FY 2012. Depending on the success of the pilot, other national laboratories will be contacted for interest.

\subsection{Experiment Support}

ATR NSUF irradiation experiments typically run for three or more years and PIE-only experiments typically run for two years. This can create a funding challenge for university faculty attempting to involve graduate students in an ATR NSUF experiment. To help the universities maintain continuity of students, it was decided at the inception of the ATR NSUF program that a portion of the budget would be made available to the universities to support miscellaneous costs. This budget set-aside has been termed "bridge funding" and in 2010 guidelines were established setting parameters for providing this funding to universities who meet the criteria. The amount of budget required in this area has been relatively stable over the past two years with the slow-down in award of irradiation and PIE-only research projects. As the number of ATR NSUF experiments grows, it is anticipated that the need for bridge funding will grow accordingly.

\subsection{Review Boards}

The Scientific Review Board (SRB) is the independent oversight body that helps to ensure the ATR NSUF is performing its intended scientific mission. The SRB operates under a charter approved by the INL Deputy Director for Science and Technology and advises the Deputy Director on the performance of the ATR NSUF in meeting its objectives. The Board meets once per year, and time and travel expenses are offered to members for these meetings. In addition, an ATR NSUF Industry Advisory Committee (ANAIC) exists to provide input into determining capabilities needed to support industry experiments. As ANAIC has matured, ATR NSUF researchers whose projects are most relevant to industry are being offered the opportunity of presenting their research results at the annual meeting; travel reimbursement is offered to these presenters.

\subsection{Users Organization}

An ATR NSUF Users Organization was formed in 2011 with the primary function of providing a channel for exchange of information, advice and best practices between the users and ATR NSUF management. This is a standard at other DOE user facilities. This organization operates under a charter and holds regular meetings. The executive committee consists of a chair, a secretary, three general board members and a student member. Positions on the executive committee rotate biannually with the 
exception of the student member which is elected annually. This organization continues to grow and influence the direction and priorities of ATR NSUF activities.

\subsection{Outreach}

Outreach activities provide a fundamental mechanism for communicating with current and potential users. This area of the program is vast and includes the ATR NSUF website (http://atrnsuf.inl.gov), sponsorships and exhibits at strategic national/international meetings, annual reports, quarterly reports, colloquium presentations, press releases, and fact sheets.

The website serves as the portal to everything from registering for Users Week to submitting a proposal. From the ATR NSUF home page, users can find information on partner facilities (including links to user guides), read the research project summaries in the annual reports, view presentations from Users Week, see press releases, and read the quarterly reports. The website's flexible format allows for quick adjustments to any aspect of the site, and over the years many changes have been made to better reflect users' needs.

Continued participation in national and international meetings, such as the American Nuclear Society (ANS), The Minerals, Metals, and Materials Society (TMS), Test Research and Training Reactors (TRTR), International Group on Research Reactors (IGORR), Expanded Halden Programme Group (EHPG), Materials Science and Technology(MST), Nuclear Materials Conference (NUMAT), Advancements in Nuclear Instrumentation, Measurement Methods and Applications (ANIMMA), International Cooperative Group on Environmentally Assisted Cracking (ICG-EAC), and Conference on Nuclear Training and Education (CONTE), provides opportunities to reach a broad audience. At some of these meetings, ATR NSUF sponsors an exhibit booth where current and potential users have an opportunity to talk with staff, receive copies of current literature, and discover future plans for the user facility. At other meetings, the primary purpose for participation is to present research results from the ATR NSUF awarded experiments and the ATR NSUF capability development research. Interactions through all these meetings have increased interest in ATR NSUF and its ability to serve as a resource for growing the nuclear energy research user community.

In 2009, ATR NSUF published its first Annual Report. This report provides a venue for showcasing ATR NSUF capabilities, highlighting program accomplishments, and includes a write-up for each research project that performed work during the previous year. The report is printed and distributed widely and an electronic version is loaded onto the ATR NSUF website. The bimonthly report will transition into a quarterly report in fiscal year 2013 to better align with the flow of the program. The quarterly report covers current ATR NSUF events such as Users Week, User Organization meetings, award of research projects and the opening and closing of proposal calls. 


\subsection{FY 2013 to 2017 Program Office Budget Requirements}

Table 5-1. Estimated expenditures (in K\$) to support the ATR NSUF Program Office activities.

\begin{tabular}{|l|c|c|c|c|c|}
\hline \multicolumn{1}{|c|}{ Budget Item } & $\mathbf{2 0 1 3}$ & $\mathbf{2 0 1 4}$ & $\mathbf{2 0 1 5}$ & $\mathbf{2 0 1 6}$ & $\mathbf{2 0 1 7}$ \\
\hline Program Administration $^{\text {a }}$ & $\$ 2,683$ & $\$ 2,737$ & $\$ 3.091$ & $\$ 3,463$ & $\$ 3,533$ \\
\hline Bridge Funding to Universities $^{\mathrm{b}}$ & $\$ 399$ & $\$ 459$ & $\$ 2,028$ & $\$ 3,024$ & $\$ 3,572$ \\
\hline Outreach $^{\mathrm{c}}$ & $\$ 28$ & $\$ 45$ & $\$ 100$ & $\$ 102$ & $\$ 104$ \\
\hline Total Program Office $^{\prime}$ & $\mathbf{\$ 3 , 1 1 0}$ & $\mathbf{\$ 3 , 3 9 4}$ & $\mathbf{\$ 5 , 3 7 6}$ & $\mathbf{\$ 6 , 7 4 9}$ & $\mathbf{\$ 7 , 3 7 1}$ \\
\hline
\end{tabular}

a. Add one additional full time program administrator in 2016.

b. In 2015, all of a project's the bridge funding will be awarded in the first year the experiment is awarded, maximum of $\$ 150 \mathrm{~K}$ for the duration of the project.

c. In 2015, start supporting presentation of ten papers per year for INL Principal Investigators. 


\section{REACTOR AND NON-REACTOR CAPABILITY ENHANCEMENTS}

The ATR NSUF, through interactions with potential users, SRB, and ANIAC ,seeks information on capabilities that, if added to the ATR, MFC, or CAES facilities, would be of use to both ATR NSUF users and the INL research community. These capability enhancements are integrated into the broader INL planning. The sections below describe capabilities added to the ATR NSUF, and suggestions for additional enhanced capability at INL that would further enhance ATR NSUF capabilities.

\subsection{Enhanced ATR Capabilities}

\subsubsection{Reactor Instrumentation}

To extract key data from user tests, sensor technologies must be implemented for in-reactor monitoring of fuel and material response to irradiation. Instrumentation included in an irradiation test depends on customer test requirements and funding. At lower flux MTRs, such as the Halden BWR, sensors are able to provide real-time data on temperature, thermal conductivity, sample elongation, creep deformation, thermal and fast flux, crud deposition, localized heating, crack growth rates, and fission gas release amount and composition. In addition, 'integral' sensors are often included in irradiation tests to quantify peak irradiation temperature and integrated fluence exposure. In-reactor instrumentation enables increased fidelity of sample performance data because measurements are made from the sample at the irradiation conditions of interested without any potential disturbance of phenomena of interest due to sample removal from the reactor. In addition, the use of in-reactor instrumentation reduces life cycle irradiation and PIE costs.

Until recently, ATR irradiations relied primarily on commercial vendors for instrumentation. However, demands for high-temperature radiation resistant sensors with increased accuracy and resolution in tests to support development of advanced fuels and materials and development of new reactor concepts have led INL to enhance sensors used at international MTRs for the higher temperature/higher flux conditions at US MTRs and to develop and deploy new sensor technologies that can better meet DOE-NE programmatic needs. In-pile instrumentation enhancement and development activities are primarily completed at INL's High-Temperature Test Laboratory (HTTL).

The ATR NSUF is building upon this instrumentation development effort. An instrumentation development and deployment strategy was implemented to transfer sensor technologies utilized at other MTRs and explore advanced technologies for in-pile applications. Research activities are prioritized based on anticipated ATR NSUF customer needs. As summarized in Table 6-1, several enhanced and new sensor technologies are now available for use in ATR NSUF facility irradiations, including tests in the ATR Loop 2A, instrumented capsules simulating high-temperature inert gas conditions, static capsules, and the HSIS. The items shown in red are currently available, blue indicates those currently under development, and black indicates those planned for development.

Table 6-1 Enhanced Sensor Technologies for ATR NSUF Irradiations.

\begin{tabular}{|l|l|l|}
\hline \multicolumn{1}{|c|}{ Parameter } & \multicolumn{1}{|c|}{ Sensor } & \multicolumn{1}{c|}{ Status } \\
\hline Temperature & Melt Wires & $\begin{array}{l}\text { Used to support various irradiation programs. Procedures completed for } \\
\text { evaluating candidate melt wires; numerous melt wires evaluated for temperatures } \\
\text { between } 85 \text { and } 1470{ }^{\circ} \mathrm{C} \text {; reference document for interpreting results issued. }\end{array}$ \\
\cline { 2 - 3 } & $\begin{array}{l}\text { SiC Temperature } \\
\text { Monitors }\end{array}$ & $\begin{array}{l}\text { Used to support various irradiation programs. Development and evaluation of } \\
\text { post-irradiation measurement capability completed [including comparison } \\
\text { evaluations with Oak Ridge National Laboratory (ORNL)]. }\end{array}$ \\
\cline { 2 - 3 } & HTIR-TCs & $\begin{array}{l}\text { Initial out-of-pile testing completed. In-pile testing (in the AGR-1 gas reactor } \\
\text { fuel irradiation test) and sensor enhancement evaluations completed; High } \\
\text { Temperature Irradiation Resistant Thermocouples (HTIR-TCs) provided to the } \\
\text { Massachusetts Institute of Technology (MIT) in 2010, and HTIR-TCs for high } \\
\left.\text { temperature (up to 1600 }{ }^{\circ} \mathrm{C}\right) \text { irradiations shipped to Institutt for Energiteknikk }\end{array}$ \\
\hline
\end{tabular}




\begin{tabular}{|c|c|c|}
\hline Parameter & Sensor & Status \\
\hline & & $\begin{array}{l}\text { (Institute for Energy Technology) at the Halden Reactor Project (IFE/HRP) in } \\
\text { November } 2011 .\end{array}$ \\
\hline & UTs & $\begin{array}{l}\text { Efforts initiated to develop and evaluate the accuracy and resolution of a } \\
\text { prototype for FCR\&D evaluations initiated in } 2011 \text {. Initial efforts focusing on } \\
\text { the use of magnetostrictive transducers, but instrumented lead test needed to } \\
\text { evaluate the irradiation survivability of piezoelectric and magnetostrictive } \\
\text { transducers (which could enhance accuracy and resolution). }\end{array}$ \\
\hline \multirow[t]{2}{*}{$\begin{array}{l}\text { Thermal } \\
\text { Conductivity }\end{array}$} & $\begin{array}{l}\text { Multiple } \\
\text { thermocouples }\end{array}$ & $\begin{array}{l}\text { Initial laboratory testing completed. Inclusion of HTIR-TCs could allow } \\
\text { detection at higher temperatures than current methods used by IFE/HRP. }\end{array}$ \\
\hline & THWM & $\begin{array}{l}\text { Prototype design developed and initial laboratory testing completed. Inclusion } \\
\text { of HTIR-TCs could allow detection at higher temperatures. Prototype Transient } \\
\text { Hot Wire Method (THWM) probe shipped to MIT in February } 2011 \text { for } \\
\text { inclusion in hydride fuel test. }\end{array}$ \\
\hline \multirow[t]{4}{*}{$\begin{array}{l}\text { Elongation, Crud } \\
\text { deposition, } \\
\text { Corrosion }\end{array}$} & LVDTs & $\begin{array}{l}\text { Out-of-pile testing completed on developmental Linear Variable Differential } \\
\text { Transformer (LVDT) that resists high temperature degradation and eliminates } \\
\text { Curie temperature effects. }\end{array}$ \\
\hline & Diameter gauge & $\begin{array}{l}\text { Currently used in Halden Boiling Water Reactor (HBWR) for detecting swelling, } \\
\text { corrosion, and crud buildup. Investigations delayed due to funding limitations. }\end{array}$ \\
\hline & $\begin{array}{l}\text { Ultrasonic } \\
\text { Techniques }\end{array}$ & $\begin{array}{l}\text { Scoping tests completed on prototype; additional prototype out-of-pile testing } \\
\text { needed. }\end{array}$ \\
\hline & $\begin{array}{l}\text { Fiber Optic } \\
\text { Techniques }\end{array}$ & $\begin{array}{l}\text { Efforts initiated in } 2011 \text { to develop and evaluate the accuracy of a candidate } \\
\text { probe. Prior to deployment, instrumented lead test needed to evaluate fiber optic } \\
\text { survivability in radiation environments. }\end{array}$ \\
\hline $\begin{array}{l}\text { In-pile Creep Test } \\
\text { Rig }\end{array}$ & $\begin{array}{l}\text { LVDT-based rig } \\
\text { with bellows }\end{array}$ & $\begin{array}{l}\text { Design developed and prototype evaluated at PWR conditions in a laboratory } \\
\text { autoclave. Enhanced design developed and fabricated. When } 2012 \text { evaluations } \\
\text { completed, enhanced design will be inserted into an ATR PWR loop. Follow-on } \\
\text { work will develop design with variable load capability. }\end{array}$ \\
\hline \multirow[t]{3}{*}{ Neutron Flux } & SPNDs & \multirow{2}{*}{$\begin{array}{l}\text { Specially-developed fixturing designed, fabricated, and installed at ATRC in } \\
\text { 2010. Additional evaluations of detectors continuing, and new fixturing being } \\
\text { fabricated to allow simultaneous placement of detectors in a flux trap. }\end{array}$} \\
\hline & Fission Chambers & \\
\hline & $\begin{array}{l}\text { Micro Pocket Flux } \\
\text { Detectors } \\
\text { (MPFDs) }\end{array}$ & Initiated development of MPFDs in 2011. \\
\hline \multirow[t]{2}{*}{ Gamma Heating } & $\begin{array}{l}\text { Gamma } \\
\text { thermometers }\end{array}$ & Currently used at HBWR; Investigations started in 2012. \\
\hline & Calorimeters & Currently used at OSIRIS; investigations delayed due to funding limitations. \\
\hline \multirow[t]{3}{*}{ Crack propagation } & $\begin{array}{l}\text { DCPD method } \\
\text { with CT specimens }\end{array}$ & $\begin{array}{l}\text { Preliminary design (based on IFE/HRP method) developed by MIT in 2009; } \\
\text { additional research started in } 2012 \text {. }\end{array}$ \\
\hline & $\begin{array}{l}\text { Ultrasonic } \\
\text { techniques }\end{array}$ & Efforts to be initiated (if funding available). \\
\hline & $\begin{array}{l}\text { Fiber optics } \\
\text { techniques }\end{array}$ & Efforts to be initiated (if funding available). \\
\hline
\end{tabular}

Funding for this effort includes sensor development and testing activities as well as activities to provide sensors in ATR NSUF irradiations. The cost for research activities to transfer sensor technology from other research and test reactors and explore advanced sensor technologies is reduced through the use of international collaborations that have been established with organizations, such as the Institute for Energy Technology at the Halden Reactor Project (IFE/HRP) in Norway and the Commissariat a l'Energie Atomique (CEA) in Cadarache, France. Staff exchanges facilitate these international collaborations. Interactions with other U.S. laboratories, such as ORNL, and with U.S. universities, such as the Massachusetts Institute of Technology, Utah State University, the University of Idaho, Idaho State University, Pennsylvania State University, and the Kansas State University, also facilitate instrumentation development and deployment activities. In addition, it should be noted that specific DOE-NE programs, 
such as the FCR\&D and NGNP programs, have funded instrumentation required for specific irradiation tests.

During 2013, the HTTL will be relocated to the first floor of the south laboratory wing, one of the two main structures in the Research and Education Laboratory (REL) building at INL, near the CAES facility. This new facility will enhance current HTTL capabilities. Specifically, it includes a clean room for sensor fabrication and space to accommodate essential equipment, such as a 3D computer tomography machine and an e-beam welder, are co-located with other HTTL equipment for sensor fabrication and evaluation. Funding for this equipment is identified in the line, "Irradiation Experiment Instrumentation" in Table 6-1. The ATR NSUF will work with other research programs INL funding organizations to enhance the HTTL by providing this essential equipment.

\subsubsection{LWR Materials Irradiation Testing}

The operation of Loop 2A in ATR also provides an opportunity to irradiate LWR structural materials (rector internals) in prototypic LWR environments, either BWR or PWR. A high degree of temperature control is attained by varying flow rate of coolant in the loop and by designing Loop 2A test trains appropriately. Two current ATR NSUF industry projects are utilizing this loop; these are an EPRI pilot project on irradiation and PIE of alloys X-750 and XM-19 that is the subject of a CRADA agreement between INL and EPRI and a work for others project with the Nuclear Regulatory Commission (NRC) involving irradiation and PIE of stainless steel alloys. It is anticipated that Loop 2A will be utilized again in FY 2014 and beyond by EPRI and NRC to irradiate thermally embrittled austenitic stainless steels and for re-irradiation of ex-plant (Zorita) materials to fluence levels representative of an 80 plus year reactor lifetime. Additionally, it is anticipated that the DOE LWRS program will utilize the center flux trap and Loop 2A for high fluence irradiation of LWR materials.

In order to ensure that all appropriate test train experimental and handling equipment is available to support experiments in Loop 2A, additional hardware and systems needed to be designed and fabricated. These are not part of the actual test loop itself (i.e., the loop can operate without these items, but an experiment cannot be performed) and are collectively named "Loop test readiness" activities. This work is expected to be completed in 2015, unless new test train designs require additional loop support hardware.

Operation of Loop 2A in ATR provides an opportunity to perform prototypic LWR fuel testing that is unique in the U.S. The LWR-S program has requested tests in Loop 2A, and it is anticipated that the FCRD program will also require testing in Loop 2A. Once the capability to irradiate LWR fuel is demonstrated in cooperative industry programs, additional industry requests for testing, including ramp testing of instrumented fuel, is anticipated in later years. The capability for ramp testing exists at ATR using the PALM system. This capability is dated and owned by Naval Reactors, and it is likely that this capability will have to be modified in some form by ATR NSUF if ATR NSUF experiments will be performed using this capability.

\subsection{Post-irradiation Examination Capability}

Basic PIE tools are present at INL MFC in the HFEF, AL, FASB, and EML, although these capabilities are generally in need of maintenance and upgrades. In FY 2010, INL acquired some of the key research tools required to develop a fundamental understanding of material and fuel response to irradiation that is required to engineer new radiation resistant materials and high burn up fuels. Radiationinduced changes that occur on the atomic scale are at the root of nearly every aspect of reactor material degradation, and phenomena that occur at this scale have real-world consequences. A major emphasis of the ATR NSUF is to develop the cutting-edge capability for detailed understanding of radiation-induced material changes and make this capability available to the nuclear energy research community. Most of the capability procured in FY 2010 was installed in the CAES building, both to allow greater access to INL collaborators and due to the lack of a suitable facility at MFC. As the ATR NSUF matures over the 
next 5 years, similar capabilities will be installed at MFC in the Irradiated Materials Characterization Laboratory (IMCL). The core capability in HFEF will be maintained and upgraded. Funding for new equipment and facility modifications to support advanced PIE capabilities will come from a variety of sources, including multi-programmatic funding for equipment used by a range of programs at the INL, including FCRD, RERTR, VHTR, LWR-S, ATR NSUF as well as others. Based on historical experience, there is a need for new instruments or upgrades to existing instruments that are identified on an emerging real-time basis. There is an item on the capability enhancement cost estimate table (Table 62) that is expected to be used annually for various equipment that has not been specifically identified at this time. The program will continue to evaluate the user needs relative to additional PIE capabilities as well as seek collaboration opportunities (to reduce ATR NSUF funding need) if additional equipment needs are identified.

\subsubsection{Hot Fuel Examination Facility}

Existing PIE equipment and instrumentation in the HFEF require periodic renewal and upgrading as equipment ages and technology evolves. The ATR NSUF works with other INL research and development programs and INL Management to identify required upgrades to this equipment to the stateof-the-art capability required to achieve good quality results at high-sample throughput. Upgrades to the precision gamma scanner and metallographic sample preparation equipment were accomplished in FY 2010. Remaining equipment to be upgraded includes Neutron Radiography Reactor (NRAD) radiography capabilities, eddy current testing capabilities, and visual examination capabilities. These capabilities are required in the long-term to continue to support DOE programs (Next Generation Nuclear Plant [NGNP], Reduced Enrichment Research and Test Reactor [RERTR], FCRD) and in the short-term to maintain a credible base capability to conduct LWR fuel examinations.

Long-term capability to conduct LWR fuel research on behalf of DOE's LWR-S and FCRD programs and industry will require the addition of a Consolidated Fuel Examination Station (CFES) and a Fuel Rod Instrumentation System (FRIS) to HFEF. The CFES will allow efficient examination of fuel rods up to $4.5 \mathrm{~m}$ long by consolidating non-destructive examinations (visual examination, gamma scanning, eddy current, length, profilometry, fission gas pressure/capture, and sectioning), freeing up equipment that is currently oversubscribed. The FRIS will allow fuel rods previously irradiated in commercial LWRs to be this capability will likely be led by the FCRD program and is not included in the ATR NSUF program planning.

\subsubsection{Irradiated Materials Characterization Laboratory}

The IMCL provides the critical capability to house high-end analytical instrumentation in a shielded environment for use on irradiated fuels and materials. The IMCL will consolidate existing capability at INL and provide purpose-built space for high-end analytical instrumentation such as an Electron Probe Micro-Analyzer (EPMA), dual-beam Focused Ion Beam (FIB), micro-X-ray Diffraction (XRD), field emission gun scanning transmission electron microscope (FEG-STEM), nano secondary ion mass spectrometer (nanosims), laser-based thermal analysis, mechanical testing, and sample preparation. The IMCL will first function as a purpose-built instrument laboratory that corrects many of the issues that currently limit equipment performance (vibration, electromagnetic fields, etc.). Another important function of IMCL is as a laboratory for developing analysis methods on irradiated materials, initially using materials that can be contact handled in a partially shielded environment. As techniques are developed and the need arises for examinations of highly active materials, the equipment will be fully shielded. Techniques for remote Raman spectroscopy will also be developed in IMCL.

Following construction of an Advanced Post-irradiation Examination and Characterization facility (APEC), which will be not be funded through the ATR NSUF program, IMCL capabilities will transition to the new facility, and IMCL will focus on mechanical testing of irradiated materials and continue to serve as a laboratory for the development of new techniques and new technologies for remote characterization of irradiated materials. 


\subsubsection{Idaho Falls Laboratory Facilities}

The Center for Advanced Energy Studies (CAES) is a public/private partnership comprised of the three Idaho public universities, private industry, and INL. The ATR NSUF staff is housed in the CAES building in Idaho Falls. CAES is a Nuclear Regulatory Commission (NRC)-licensed facility capable of handling small quantities of radiological material. CAES provides an ideal location to house high-end microstructural characterization equipment that can be made available to ATR NSUF users as part of ATR NSUF projects and to other users on an hourly basis. The suite of equipment, which will remain relatively constant over the next five years, includes the following:

- The Local Electrode Atom Probe (LEAP) is a cutting-edge instrument that allows for the study of structure and composition of materials at the atomic scale

- A FEG-STEM, used for analysis of degradation mechanisms related to nanoscale changes in composition, such as radiation-induced segregation

- A nano-indenter coupled with an Atomic Force Microscope (AFM), one of the foremost tools for measuring local mechanical properties and for imaging and measuring surfaces at the nanoscale

- A dual-beam FIB, required for fabricating specimens for LEAP, FEG-STEM, and nanoindenter cantilever beam testing. The FIB also acts as a full-featured, high-end scanning electron microscope

- Mechanical testing equipment designed for testing of small, low-dose rate specimens. Available techniques include high-temperature tensile testing, shear punch testing, fracture toughness testing, and microhardness testing

- Stress corrosion cracking (SCC) test rigs for use on unirradiated materials.

Construction of the new REL will provide additional laboratory space for non-radiological technique development and training activities. These new laboratories will also include space for an aberration corrected transmission electron microscope that will be used to examine non-radiological samples or minute quantity radiological samples manufactured in the CAES FIB having non-detectable activity levels. In addition, the new REL building will allow extension (in future years) of the current capabilities in CAES to include surface science equipment such as Auger Electron Microprobe (AEM), Secondary Ion Mass Spectroscopy (SIMS) and Electron Spectroscopy for Chemical Analysis/X-ray Photoelectron Spectroscopy (ESCA/XPS). The design of the REL facility is such that laboratory space can be readily repurposed as programs evolve or new missions develop; particular equipment selections will be made based on needs at the time and available funding. The combination of the current CAES building and the new REL laboratory space allotted to ATR NSUF will form a gateway for users interacting with the INL in its role as a national user facility allowing for greater opportunities for user training and education.

\subsubsection{LWR-relevant Capability}

Many current fuels and materials issues that affect commercial nuclear plant operation, reliability, and license extension remain to be addressed. As the U.S. nuclear fleet ages, the realization that there is a large economic benefit (potentially $\$ 300$ billion) in extending plant lifetimes beyond 60 years will drive additional research into materials degradation. With this renewal of interest in research also comes the opportunity for advances in materials for new reactors. The U.S. nuclear industry also continues to push for increases in fuel reliability. This has led to the development of improved fuel systems that incorporate corrosion-resistant cladding materials and features that improve resistance to pellet-cladding interaction. New fuels will require ramp testing in research reactors prior to deployment.

Based on a multi-tiered approach to interacting with industry, the ATR NSUF will invest in the capability to meet LWR-specific research needs primarily in two areas: Irradiation Assisted Stress 
Corrosion Cracking (IASCC) and improved fuel examination capability. Defining the test capability needs will be done in close cooperation with the EPRI, NRC, and reactor vendors.

To meet the need for IASCC testing, ATR Loop 2A is available and two IASCC test rigs have been built and are due to be operational in 2013 in FASB at the MFC. An additional two IASCC test rigs are planned for the 2015-2017 timeframe to meet anticipated demand. A Raman spectrometer system will be developed for remote use to allow examination of the corrosion layers formed on irradiated materials and fuels during operation in commercial plants. Additionally, due to recognized limitations in facility space at MFC, IASCC systems will be established at the partner facility at the University of Michigan. This combined irradiation and testing capability will be unique in the world.

Improvements to LWR fuel examination capability center around the installation of a consolidated fuel examination station. This system will perform all non-destructive fuel examinations and fuel sectioning at one window in HFEF, without multiple transfer and repositioning operations. This system will be capable of examining 4.5-m-long commercial fuel rods as well as smaller specimens from DOE programs. The lead for this effort is in the FCRD program and will not be funded by the ATR NSUF.

The core capability to conduct fuel ramp testing involves acquisition of a fuel instrumentation system for installation in HFEF and development of a capability similar to the PALM used by Naval Reactors at ATR. The fuel instrumentation system is available commercially from the Halden reactor for less than \$2 M (10.7 M NOK, Norwegian currency; this cost does not include installation). This is not currently planned for ATR NSUF in the near future, but will likely be added in a longer range planning period.

All of the LWR-relevant capability established is open to any user, and projects are anticipated from industry, universities, and laboratories.

\subsection{FY 2013 - 2017 Capability Enhancements Budget Requirements}

Table 6-2. Estimated expenditures (in K\$) to support capability enhancement.

\begin{tabular}{|l|c|c|c|c|c|}
\hline \multicolumn{1}{|c|}{ Budget Item } & $\mathbf{2 0 1 3}$ & $\mathbf{2 0 1 4}$ & $\mathbf{2 0 1 5}$ & $\mathbf{2 0 1 6}$ & $\mathbf{2 0 1 7}$ \\
\hline $\begin{array}{l}\text { Irradiation Experiment } \\
\text { Instrumentation }\end{array}$ & $\$ 879$ & $\$ 897$ & $\$ 1,040$ & $\$ 1,060$ & $\$ 1,082$ \\
\hline ATR PWR Loop Readiness & $\$ 425$ & $\$ 100$ & $\$ 100$ & & \\
\hline PIE Instruments & $\$ 202$ & $\$ 206$ & $\$ 500$ & $\$ 510$ & $\$ 520$ \\
\hline Focused Ion Beam (FIB) & $\$ 825$ & & & & \\
\hline IASCC test rigs & $\$ 1,293$ & & & & \\
\hline Aberration Corrected TEM & & & $\$ 200$ & $\$ 5,000$ & \\
\hline Nanosims & & & & & $\$ 4,000$ \\
\hline $\begin{array}{l}\text { Mechanical testing \& sample } \\
\text { preparation }\end{array}$ & & & & $\$ 1,000$ & \\
\hline Equipment shielding & & & & $\$ 2,000$ & \\
\hline Total Capability Enhancement & $\mathbf{\$ 3 , 6 2 4}$ & $\mathbf{\$ 1 , 2 0 2}$ & $\mathbf{\$ 1 , 8 4 0}$ & $\mathbf{\$ 9 , 5 7 0}$ & $\$ \mathbf{6 , 5 0 1}$ \\
\hline
\end{tabular}




\section{ATR NSUF Total Projected Funding Needs for FY 2013 to 2017}

Table 7-1. Estimated expenditures (in K\$) to support all ATR NSUF functions.

\begin{tabular}{|l|c|c|c|c|c|}
\hline \multicolumn{1}{|c|}{ Program Element } & $\mathbf{2 0 1 3}$ & $\mathbf{2 0 1 4}$ & $\mathbf{2 0 1 5}$ & $\mathbf{2 0 1 6}$ & $\mathbf{2 0 1 7}$ \\
\hline Reactor Experiments & $\$ 5,320$ & $\$ 7,743$ & $\$ 12,417$ & $\$ 14,946$ & $\$ 17,608$ \\
\hline Post Irradiation Experiments & $\$ 3,695$ & $\$ 5,732$ & $\$ 7,717$ & $\$ 11,039$ & $\$ 14,026$ \\
\hline Education Programs & $\$ 740$ & $\$ 1,077$ & $\$ 1,162$ & $\$ 1,185$ & $\$ 1,209$ \\
\hline Program Office & $\$ 3,110$ & $\$ 3,394$ & $\$ 5,376$ & $\$ 6,749$ & $\$ 7,371$ \\
\hline Capability Enhancements & $\$ 3,624$ & $\$ 1,202$ & $\$ 1,839$ & $\$ 9,570$ & $\$ 6,501$ \\
\hline Total ATR NSUF Program & $\mathbf{\$ 1 6 , 4 8 9}$ & $\mathbf{\$ 1 9 , 1 4 8}$ & $\mathbf{\$ 2 9 , 5 1 1}$ & $\mathbf{\$ 4 3 , 4 9 0}$ & $\mathbf{\$ 4 6 , 7 1 7}$ \\
\hline
\end{tabular}

